\title{
Miniature robotic guidance for spine surgery
}

\author{
Y. Barzilay, L. Kaplan and M. Liebergall \\ Spine Unit, Department of Orthopaedic Surgery, \\ Hadassah-Hebrew University Medical Center, Jerusalem
}

Israel

\section{Introduction}

Instrumented spinal fusion surgery is increasingly performed in the treatment of degenerative disorders, Spondylolisthesis, deformity, trauma and tumors affecting the spine (Davis, 1994; Katz, 1995). In-vitro and In-vivo studies using the free hand or fluoroscopically assisted techniques documented breaching of the pedicle in 3-55\% (Amiot et al., 2000; Belmont et al., 2001; Belmont et al., 2002; Boachie-Adjei et al., 2000; Carbone et al., 2003; Castro et al., 1996; Esses et al., 1993; Farber et al., 1995; Gertzbein \& Robbins, 1990; Laine et al., 1997a; Laine et al., 1997b; Laine et al., 2000; Liljenqvist et al., 1997; Lonstein et al., 1999; Odgers et al., 1996; Schulze et al., 1998; Suk et al., 1995; Vaccaro et al., 1995a; Vaccaro et al. 1995b; Weinstein et al., 1998; Xu et al., 1998)

Clinically significant screw misplacements however occur in 0-7\% (Amiot et al. 2000; Belmont et al.2002; Belmont et al. 2001; Boachie-Adjei et al. 2000; Carbone et al. 2003; Castro et al. 1996; Esses et al. 1993; Farber et al. 1995; Gertzbein \& Robbins, 1990; Laine et al. 2000; Laine et al. 1997a; Liljenqvist et al. 1997; Lonstein et al. 1999; Odgers et al. 1996; Schulze et al. 1998). Neuro-monitoring, neuro-stimulation, and computed assisted navigation systems reduce the incidence of screw misplacement, however none of them has gained significant popularity in spine surgery, mainly due to logistical and cost-effectiveness issues such as the need for dynamic referencing and a line-of sight, extra staff, expensive tools and cumbersome procedures, longer operation time and the high cost of the capital equipment (Berlermann et al. 1997; Bolger \& Wigfield, 2000; Carl et al. 1997; Choi et al. 2000; Digioia et al. 1998; Ebmeier et al. 2003; Foley \& Smith, 1996; Girardi et al. 1999; Glossop et al. 1996; Kalfas et al. 1995; Kim et al. 2001; Laine et al. 1997b; Merloz et al. 1998; Mirza et al. 2003; Rampersaud et al. 2001; Rampersaud and Foley, 2000; Raynor et al. 2002; Reidy et al. 2001; Schlenzka et al. 2000; Schwarzenbach et al. 1997; Simon and Lavallee, 1998; Welch et al. 1997).

Surgical robots have emerged during the 1990's and offer distinct added value in terms of accuracy and minimally-invasiveness of the surgical procedure. However, current systems are extremely expensive and large in size, and typically require immobilization of the patient (Taylor \& Stoianovici, 2003). The SpineAssist ${ }^{\circledR}$ (Shoham et al. 2003) (Mazor Surgical Technologies, Caesarea, Israel) is a bone-mounted miniature robotic guidance system, clinically and experimentally validated for spinal surgery (Barzilay et al. 2006, Lieberamn et al 2006; Togawa et al. 2007). It facilitates image-based semi-active guidance for providing high accuracy in the positioning of surgical tools and implantable devices such as Pedicle 
screws, Kyphoplasty needles, tumor evacuators and more. To the best knowledge of the authors, no other clinically validated robotic system is available today for spine surgery. In a recent publication (Barzilay et al. 2006) technical issues as well as patient-related and surgeon-related issues encountered during the clinical development phase were analyzed and lead to improvements in software and in robotic tools. Ways were offered to reduce errors and shorten the learning curve when new users are introduced to this system. In this chapter, a short summary of the clinical development phase and an overview of the early routine clinical use of the SpineAssist in procedures involving pedicle screws insertion, kyphoplasty, vertebroplasty and biopsy of the spine are presented. Also describes is the very early usage of the system in deformity surgery.

The SpineAssist ${ }^{\circledR}$ (SA) (Fig. 1) is a miniature bone-mounted robot - 2.5 inch diameter, 250 gram - featuring a six-degree-of-freedom parallel design.

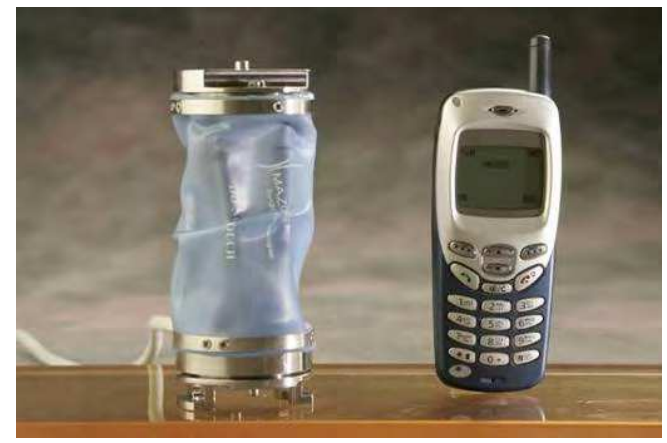

Figure 1. The SpineAssist miniature robot

The miniature robot is connected to the SA workstation (Fig. 2), which controls its motion and runs specially designed graphic user-interface software.

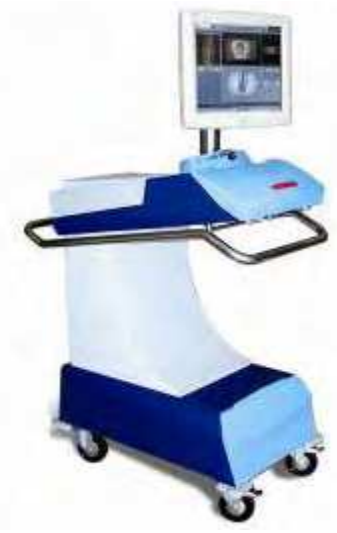

Figure 2. The SpineAssist Workstation

The system is semi-active, in that it guides the surgeon to the desired implant positions according to his/her preoperative plan, while leaving the actual surgical act in the physician's hands. The concept is of pre-operative planning and intra-operative execution. The planning is done on a 3-D model of the patient's spine generated by the system based 
on a CT scan (Fig. 3). The plan includes implant sizing and placements for all the levels of the spine to be operated on, and can be done on the workstation itself or on the physician's laptop or desktop computer.

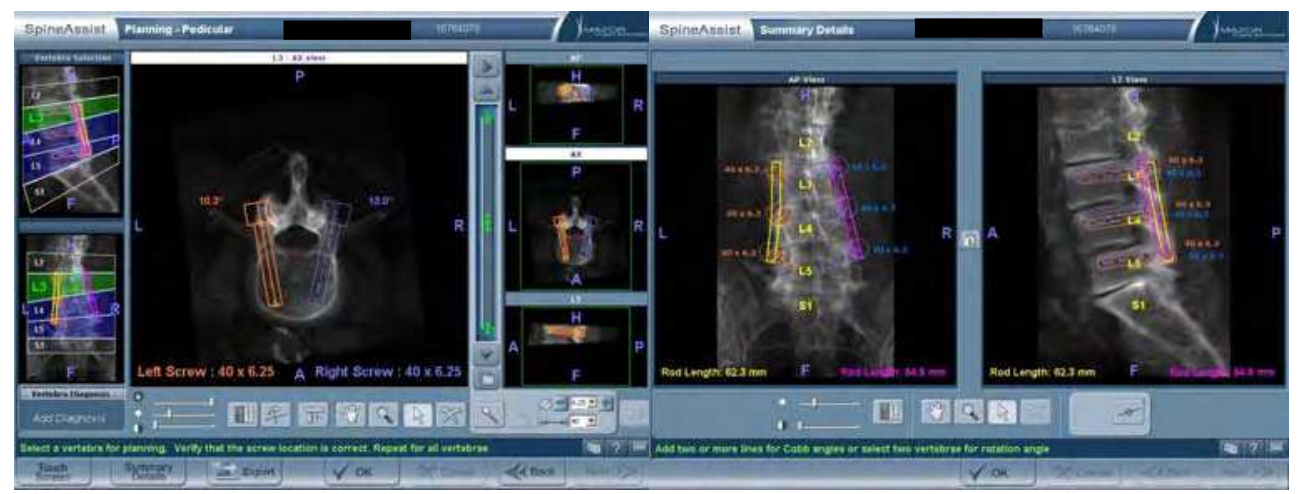

Figure 3. 3D planning of pedicle screws to be introduced into L3 vertebra and a summary of a plan for L3-4-5 fusion

In preparation for the intraoperative execution of the plan, the SA workstation is connected by means of a BNC video cable to a C-Arm fluoroscopy imaging machine and two blank images - anterior-posterior (AP) and $60^{\circ}$ Oblique - are taken with a special Image Calibrator attached to the image intensifier of the C-Arm. These two "blank" images are used by the system to automatically compensate for distortions due to ambient magnetic fields and other sources of distortion to the intraoperative fluoroscopy images. The miniature robotic device is also verified for calibration prior to every case by using a specially designed jig with 3 marker holes at positions that are known to the software. The entire process of image and robot calibration takes about 10 minutes and is performed by the radiology technician during the setup of the OR for surgery - parallel to other preparations and prior to bringing the patient in. As the operation begins, a minimally-invasive Hover-T® frame or a lessinvasive spinous-process clamp (Fig. 4) is attached to the patient's bony anatomy.

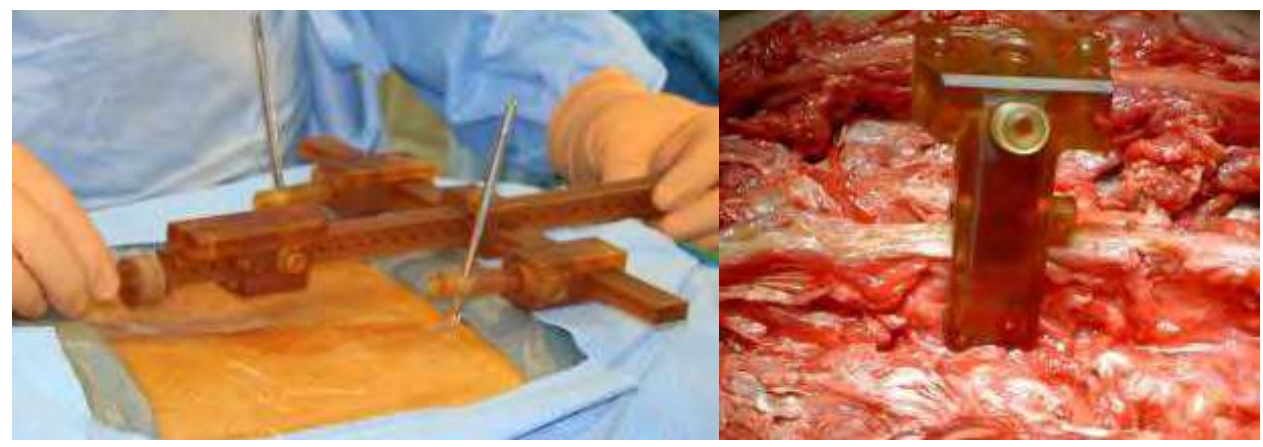

Figure 4. The clamp (right) and the Hover-T frame (left) firmly connect the robot to the patient's body

Two fluoroscopic images are taken - AP and $60^{\circ}$ oblique - with a targeting device attached to the Hover-T / Clamp. The system performs automatic, per-vertebra, matching of these 
intra-operative fluoroscopic images with the pre-operative CT. The accuracy of this process, also referred to as the image registration process, is visually verified by the surgeon; the first level to be operated on is then selected. The target is removed, the SA device is mounted onto the clamp/frame and the system controls its motion so that it points to the exact entry point and trajectory according to the surgeon's pre-operative plan. Based on the known kinematical properties of the system and the desired entry point relative to the robot base the system instructs the surgeon to attach one of three guiding arms (short- 1 medium- 2 or long-3) to the top plate of the robotic platform, through which surgical tools are inserted by the surgeon to facilitate introduction of the implant. The three arms cover the entire workspace necessary for a variety of spinal procedures. An open approach may be used (Fig. 5), as well as MIS (minimally invasive) and percutaneous approaches (Fig. 6).

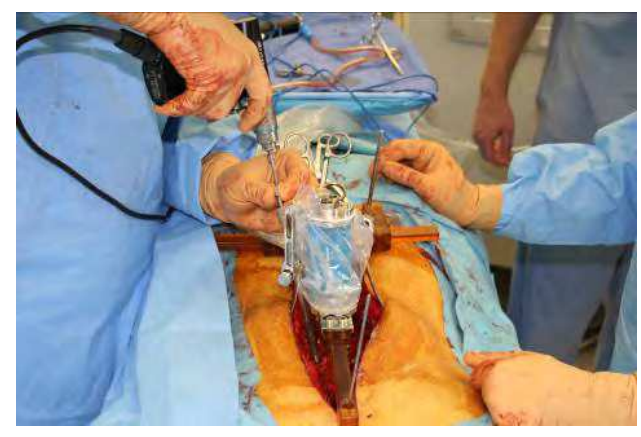

Figure 5. Intraoperative open approach, notice the tool guide through which the surgical tools are inserted
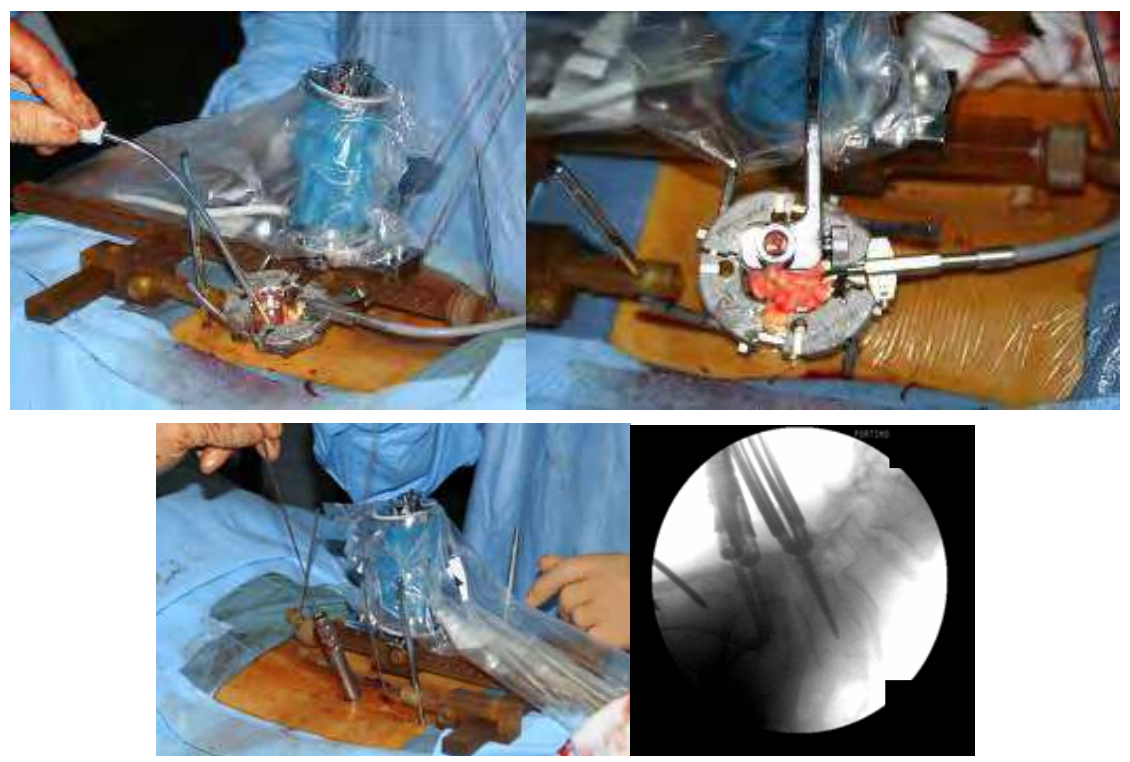

Figure 6. Intraoperative minimally invasive surgery (MIS, upper left and right) and percutaneous (lower left and right) approaches 
Fifteen patients were operated on during the clinical development phase of the Spine Assist in two spine centers (March to November 2005) with obstacles occurring in 9 cases (Barzilay et al. 2006). These obstacles were defined as related to surgeon, technique, software or equipment. Conclusions drawn during this period led to improvements in all aspects mentioned. The software was improved, making it more robust, easier to use and better in terms of pre-operative planning. Improvement in the robot's tools made them more user friendly and less prone to skiving by soft tissues. As for surgeon related errors - The clamp must be secured tightly to the spinous process in order to avoid unwanted mobility leading to errors in entry point and trajectory. Minimal force should be used when using the SA and no foreign bodies (i.e. surgical gauze) should be left in the surgical field during acquisition of fluoroscopy images or during operation of the robot. Routine clinical usage of the SA in the authors institution commenced in September 2006. The SA guidance was used by the authors in 24 procedures including 19 spinal fusions, 4 kyphoplasy/vertebroplasty and 1 biopsy. The demographic data and indications for surgery of the study group are summarized in table 1 .

\begin{tabular}{|l|l|l|}
\hline Number of patients & 24 & $\begin{array}{l}18 \mathrm{~F} \\
6 \mathrm{M}\end{array}$ \\
\hline Age (Years) & $61(24-75)$ & \\
\hline Indications & Related to degenerative disorders & 19 \\
\hline & Vertebral compression fractures & $\begin{array}{l}\text { Osteoporotic 3 } \\
\text { Metastatic 1 }\end{array}$ \\
\hline & Infection & Spondylodiscitis 1 \\
\hline
\end{tabular}

Table 1. Demographic data and indications for surgery

\begin{tabular}{|l|l|l|l|l|}
\hline Total & Primary & Revisions & & \\
\hline 24 & 21 & 3 & & \\
\hline Procedure & 1-Level & 2-Level & 3-Level & 4-Level \\
\hline TLIF + Posterior fixation & 8 & 7 & & 1 \\
\hline PDPLF & 2 & & & \\
\hline Vertebroplasty & 2 & & & \\
\hline Kyphoplasty & 2 & & & \\
\hline Craig needle biopsy & 1 & & & \\
\hline
\end{tabular}

Table 2. SpineAssist guided surgical procedures

A detailed account of each surgery was taken during the procedure, with attention being paid to system and team performance during all preoperative and intraoperative stages. The ability of the system to successfully accomplish each stage of the procedure was recorded, including importing patient's CT, planning, C-Arm and robot calibration, fluoro acquisition, CT-to-fluoro registration, finding the appropriate kinematical solution for guidance, utility of the surgical accessories and overall accuracy of placements. Surgical data included time measurements of total procedure, time from attachment of clamp/hover-t to detachment, time of fluoro utilization, number of planned screw/needles and the number of executed screws/needles. Parallel to the routine use of the SA in "simple" fusion cases, Kyphoplasty and biopsy, the system was used in three deformity cases, one Scheuermann's kyphosis (80 degrees Cobb T3-T12), one Juvenile idiopathic scoliosis of 78 degrees with pedicle diameter ranging from 3 to $4.5 \mathrm{~mm}$ and one case of congenital scoliosis with a hemi vertebra of L2-3 
partially segmented from L2. Data from these cases were excluded from results as they were not considered routine. These cases will be further discussed later in this chapter. Table 2 summarizes the surgical procedure performed with SA guidance.

Three cases are presented in figures 10 to 12; these cases demonstrate the abilities of the SA to accurately guide implants or needles. In the first case (Fig. 10) the vertebroplasty needle was aimed at a void in the lower end plate of L3 caused by an osteoporotic fracture.

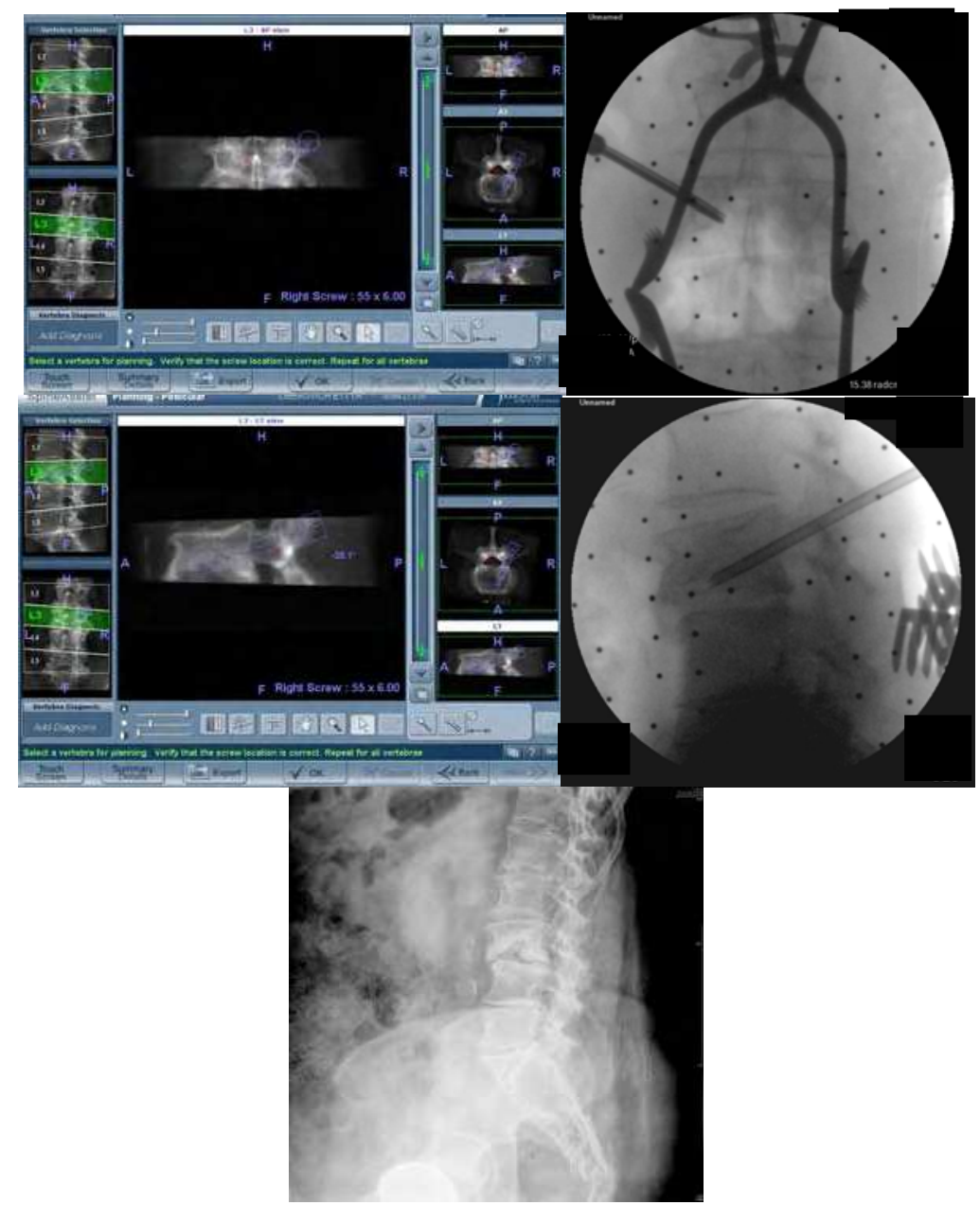

Figure 10 a-f. A 60 years old lady with corticosteroid induced osteoporotic fracture of the inferior endplate of L3 and recess stenosis of L4 presented with intractable low back pain and $\mathrm{rt}$ L4 radicular pain unresponsive to non operative treatment. She underwent SA guided L3 Vertebroplasty followed by bilateral L3-4 decompression. The vertebroplasty needle was aimed at a void in the inferior endplate of L3. Axial planning and AP fluoro are reversed in directions, but represent same anatomical sides 
In the second case (Fig. 11), 4 cannulated pedicular screws were implanted with SA guidance, again according to the preoperative plan.
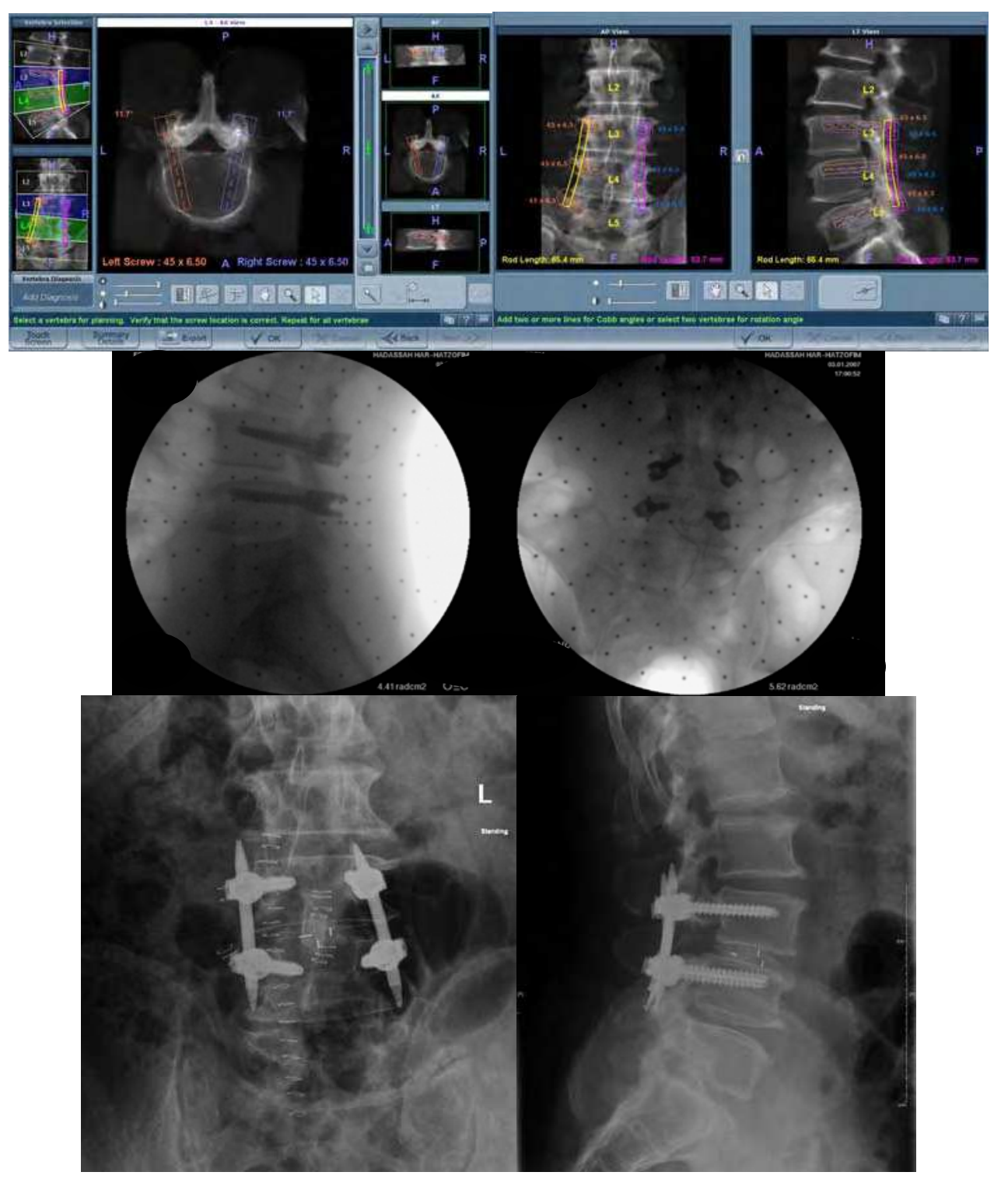

Figure 11 a-f. Preplanning and execution of L3-4 fusion, using cannulated screws. The L5 screws were planned in order to improve the segmentation process of the SA work station 
In the third case (figure 12), pedicular screws were used in a lady with lumbar scoliosis denovo. The intra-operative fluoroscopy images document how close the execution is to the plan.
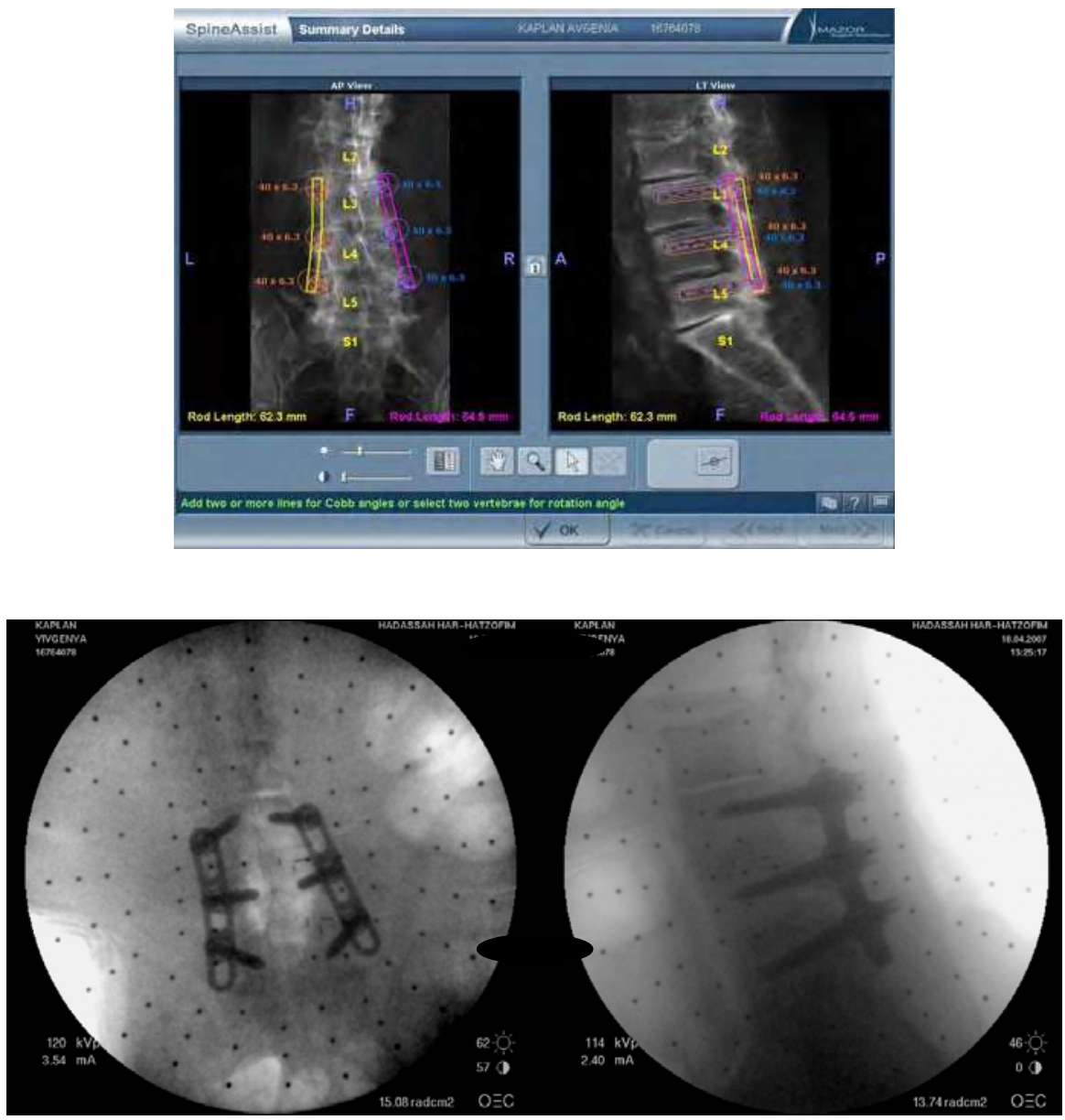

Figure 12 a-c. Planning summary and execution on a 70 years old lady with back pain and spinal intermittent claudication with lumbar scoliosis de-novo and spinal stenosis of L3-5. The surgical procedure included TLIF of L3-4 L4-5, bilateral decompression and SA guided posterior fixation of L3-4-5. The fluoroscopy images represent true AP and Lateral views of the operated levels

Data summarizing the SA usage is shown in tables 3 and 4 . Table 3 contains data regarding time measurement in the use of the SA, including time from clamp attachment to detachment (instrumentation time without plates) and total procedure. Table 4 details clinical success (defines as screw in acceptable clinical position and according to plan). 


\begin{tabular}{|l|l|l|}
\hline & Average & Range \\
\hline Screws per case & 3.7 & $1-6$ \\
\hline Total case time (Min) & 186 & $47-298$ \\
\hline $\begin{array}{l}\text { SpineAssist time per case = } \\
\text { instrumentation time without plates (Min) }\end{array}$ & 39 & $17-95$ \\
\hline SpineAssist Time per screw (Min) & 10.2 & $4.25-38$ \\
\hline
\end{tabular}

Table 3. SA usage compared to whole procedure, instrumentation time in total and perscrew

\begin{tabular}{|l|l|l|}
\hline & Total & Range \\
\hline Entry points & 89 & $1-6(3.7$ average per-case $)$ \\
\hline Success rate & $85 \%$ & $0-100 \% * *$ \\
\hline $\begin{array}{l}\text { Success rate excluding } \\
\text { technical failures* }\end{array}$ & $95 \%$ & $66-100 \% * *$ \\
\hline
\end{tabular}

* Technical failures leading to abandonment of SA procedure

** $0 \%$ and 25 success rates in 2 cases where technical failures prevented robot usage

${ }^{* * *} 66 \%$ in a case where gauze was left in the field, blocking the robot's arm from attaching to the bone, deviating two entry points

Table 4. Clinical success rates

The SA was first used in one level, "simple" fusion cases. Each step was carried out with great care, paying attention to every technical detail, which led to prolonged procedures. A strategic decision was taken to drill the entry point under fluoro guidance (AP and Lateral) in a similar manner to needle insertion in vertebroplasty, and then to verify the drill hole using probes and finders. In the first few cases entry point were found to be higher and lateral relative to the accessory process. Comparing the planning screen to the entry point position, it was found that the robot executed the plan accurately. These early planning errors led to further software improvements - the planning screen now enables a "film" in axial, coronal and sagittal planes, improving surgeon's 3-D understanding of planned implant position. Implementation of the lessons learned in the first few cases led to higher success rates, quicker procedures and minimized fluoroscopy usage (range of SA procedure time and success rates - tables 3 and 4). Later on in the series the SA was used in more levels and in cases with degenerative deformities such as Spondylolisthesis and lumbar scoliosis 
de-novo. After gaining enough confidence and experience, percutaneous cannulated pedicular screws were inserted, leading to a smaller surgical exposure, easier recovery and a better cosmetic result. Of the 24 procedures in the series, technical failures were encountered in two, and surgeon related errors occurred in two. These failures and possible solutions for future users are summarized in table 5.

\begin{tabular}{|l|l|l|}
\hline Case \# & Failure & Solution \\
\hline 1 & Technical failure of robot arm & Production process modified \\
\hline 16 & Gauze left in field & $\begin{array}{l}\text { Check before mounting clamp } \\
\text { Gauze seen on fluoroscopy }\end{array}$ \\
\hline 17 & Faulty cable & Have extra set of equipment \\
\hline 24 & Clamp moved & $\begin{array}{l}\text { Check clamp stability } \\
\text { If wrong entry point reassess } \\
\text { Re-position and repeat fluoro } \\
\text { acquisition }\end{array}$ \\
\hline
\end{tabular}

Table 5. Failure analysis and solutions for future users

As mentioned above, the system was used in 3 cases of spinal deformity. In the first case of a teenaged male with painful Scheuermann's kyphosis measuring 80 degrees the Hover-T frame was used, the system passed all stages successfully but, being attached to a rigid frame, relatively far away from the patient's body, the robot was unable to reach the desired angles and the procedure was aborted. In the second case- a teenaged boy with progressive lumbar congenital scoliosis (Hemi vertebra L2-3 RT) the clamp was used. The system guided excellent entry points into the pedicles above the hemi vertebra, but failed to recognize entry points distal to the hemi vertebra. This case is being studied at the R\&D department. In the $3^{\text {rd }}$ case of a teenage patient with idiopathic scoliosis measuring 80 degrees and with tiny pedicles $(3-4.5 \mathrm{~mm})$ registration failed using the Hover-T frame. However, when the clamp replaced the Hover-T the system performed well leading to perfect entry points and trajectories. At this stage the authors consider the usage of the SA in cases with deformity as early learning curve. A new Hover-T frame with more flexibility in positioning and an improved range of motion may enable percutaneous screw insertion in deformity cases and will upgrade these difficult procedures substantially. Another technical difficulty encountered during this series was the acquisition of high quality AP fluoroscopy images in the transition area between the chest support of the Jackson frame and air surrounding the abdomen, especially in patients with osteoporosis. In short procedures such as vertebroplasty, involving T7-10, the authors prefer to use the OSI plate, having a uniform "background", leading to easier fluoroscopy acquisition.

In conclusion, the SpineAssist is a highly accurate surgical guidance system, incorporating a bone-mounted miniature robot and unique image registration software. The system has been validated, is routinely used in the author's institution and is undergoing further evolution, expanding its work volume and the indication for its use. At the same time, it is a delicate system, especially sensitive to mechanical overload. While excess forces exerted to 
different parts of the robot and its attachments will generally not damage it, they may well affect the system's accuracy in guiding the surgeon to the desired position. Special care should be taken to follow the recommended, gentle, surgical technique and to utilizing the appropriate tools and surgical accessories. Careful attention should also be given to the preoperative plan - which becomes an integral part of the surgery - and to intra-operatively acquiring high-quality fluoroscopic images. When these simple rules are followed, and simple errors mentioned earlier are avoided, excellent results should be expected. Looking forward into the future we recommend that the working volume of the robot be increased, for example by means of modified designs of the guiding arms and robot attachments to the body; this will facilitate the utilization of the system for patients with extreme deformities or with tiny tumors (i.e. osteoid osteoma) in "unreachable" locations, in which we believe it will have a significant added value.

\section{References}

Amiot, L.P. et al. (2000). Comparative results between conventional and computer-assisted pedicle screw installation in the thoracic, lumbar, and sacral spine. Spine, Vol. 25, No. 5, (March 2000) 606-614, ISSN: 0362-2436

Barzilay, Y. et al. (2006). Miniature robotic guidance for spine surgery - introduction of a novel system and analysis of challenges encountered during the clinical development phase at two spine centres. Int J Med Robot, Vol. 2, No. 2, (June 2006) 146-53, ISSN: 1478-5951

Belmont, P.J. et al. (2001). In vivo accuracy of thoracic pedicle screws. Spine, Vol. 26, No. 21, (November 2001) 2340-2346, ISSN: 0362-2436

Belmont, P.J. et al. (2002). Accuracy of thoracic pedicle screws in patients with and without coronal plane spinal deformities. Spine, Vol. 27, No. 14, (July 2002) 1558-1566, ISSN: 0362-2436

Berlermann, U. et al. (1997) Planning and insertion of pedicle screws with computer assistance. J Spinal Disord., Vol. 10, No. 2, (April 1997) 117-124, ISSN: 0895-0385

Boachie-Adjei, O. et al. (2000). Safety and efficacy of pedicle screw placement for adult spinal deformity with a pedicle-probing conventional anatomic technique. J Spinal Disord., Vol. 13, No. 6, (December 2000) 496-500, ISSN: 0895-0385

Bolger, C. \& Wigfield, C. (2000). Image-guided surgery: Applications to the cervical and thoracic spine and a review of the first 120 procedures. J Neurosurg, Vol. 92, No. 2, (April 2000) 175-180, ISSN: 0268-8697

Carbone, J.J., Tortolani, P.J., \& Quartararo, L.G. (2003). Fluoroscopically assisted pedicle screw fixation for thoracic and thoracolumbar injuries: Technique and short-term complications. Spine, Vol. 28, No. 1, (January 2003) 91-97, ISSN: 0362-2436

Carl, A.L. et al. (1997). In-vitro simulation: Early results of stereotaxy for pedicle screw placement. Spine, Vol. 15, No. 22, (May 1997) 1160-1164, ISSN: 0362-2436

Castro, W.H. et al. (1996). Accuracy of pedicle screw placement in lumbar vertebrae. Spine, Vol. 21, No. 11, (June 1996) 1320-1324, ISSN: 0362-2436

Choi, W.W., Green, B.A., \& Levi, A.D.O. (2000). Computer-assisted fluoroscopic targeting system for pedicle screw insertion. Neurosurgery, Vol. 47, No. 4, (October 2000) 872878, ISSN: 0148-396X

Davis, H. (1994). Increasing rates of cervical and lumbar spine surgery in the United States 1979-1990. Spine, Vol. 19, No. 10, (May 1994) 1117-1124, ISSN: 0362-2436 
DiGioia, A., Jaramaz, B., \& Colgan, B. (1998). Computer Assisted Orthopaedic Surgery: Image Guided and Robotic Assistive Technologies. Clin Orthop Relat Res, Vol. 354, (September 1998) 8-16, ISSN: 0009-921X

Ebmeier, K., Giest, K., \& Kalff, R. (2003). Intraoperative computerized tomography for improved accuracy of spinal navigation in pedicle screw placement of the thoracic spine. Acta Neurochir Suppl., Vol. 85, (2003) 105-113, ISSN: 0065-1419

Esses, S.I., Barton, L.S., \& Vadim, D. (1993). Complications associated with the technique of pedicle screw fixation: A selected survey of ABS members. Spine, Vol. 18, No. 15, (November 1993) 2231-2239, ISSN: 0362-2436

Farber, G.L. et al. Accuracy of pedicle screw placement in lumbar fusions by plain radiographs and computed tomography. Spine, Vol. 20, No. 13, (July 1995) 14941499, ISSN: 0362-2436

Foley, K.T., \& Smith, M.M. (1996). Image-guided spine surgery. Neurosurg Clin N Am, Vol. 7, No. 2, (April 1996) 171-186, ISSN: 1042-3680

Gertzbein, S.D., \& Robbins, S.E. (1990). Accuracy of pedicular screw placement in vivo. Spine, Vol. 15, No. 1, (January 1990) 11-14, ISSN: 0362-2436

Girardi, F.P. et al. (1999). The placement of lumbar pedicle screws using computerised stereotactic guidance. J Bone Joint Surg Br., Vol. 81, No. 5, (September 1999) 825-9, ISSN: 0301-620X

Glossop, N.D., Hu, R.W., \& Randle, J.A. (1996). Computer-aided pedicle screw placement using frameless stereotaxis. Spine, Vol. 21, No. 17, (September 1996) 2026-2034, ISSN: 0362-2436

Kalfas, I.H. et al. (1995). Application of frameless stereotaxy to pedicle screw fixation of the spine. J Neurosurg., Vol. 83, No. 4, (October 1995) 641-7, ISSN: 0022-3085

Katz, J.N. (1995). Lumbar spine fusion. Surgical rates, costs and complications. Spine, Vol. 20, No. 24, (December 1995) 78S-83S, ISSN: 0362-2436

Kim, K.D. et al. (2001). Computer-assisted thoracic pedicle screw placement: An in vitro feasibility study. Spine, Vol. 26, No. 4, (February 2001) 360-364, ISSN: 0362-2436

Laine, T. et al. (1997a). Accuracy of pedicle screw insertion: a prospective CT study in 30 low back patients. Eur Spine J, Vol. 6, No. 6, (1997) 402-405, ISSN: 0940-6719

Laine, T. et al. (1997b). Improved accuracy of pedicle screw insertion with computer-assisted surgery: A prospective clinical trial of 30 patients. Spine, Vol. 22, No. 11, (June 1997) 1254-1258, ISSN: 0362-2436

Laine, T. et al. (2000). Accuracy of pedicle screw insertion with and without computer assistance: A randomized controlled clinical study in 100 consecutive patients. Eur Spine J, Vol. 9, No. 3, (June 2000) 235-240, ISSN: 0940-6719

Lieberman, I.H. et al. (2006). Bone-mounted miniature robotic guidance for pedicle screw and translaminar facet screw placement: Part I--Technical development and a test case result. Neurosurgery. Vol. 59, No. 3, (September 2006) 641-650, ISSN: 0148-396X

Liljenqvist, U.R., Halm, H.F., \& Link, T.M. (1997). Pedicle screw instrumentation of the thoracic spine in idiopathic scoliosis. Spine, Vol. 22, No. 19, (October 1997) 22392245, ISSN: 0362-2436

Lonstein, J.E. et al. (1999). Complications associated with pedicle screws. J Bone Joint Surg Am, Vol. 81, No. 11, (November 1999) 1519-1528, ISSN: 0021-9355

Merloz, P. et al. (1998). Pedicle screw placement using image-guided techniques. Clin Orthop Relat Res, Vol. 354, (September 1998) 39-48, ISSN: 0009-921X 
Mirza, S.K. et al. (2003). Accuracy of thoracic vertebral body screw placement using standard fluoroscopy, fluoroscopic image guidance, and computed tomographic image guidance: A cadaver study. Spine, Vol. 28, No. 4, (February 2003) 402-413, ISSN: 0362-2436

Odgers, C.J. et al. (1996). Accuracy of pedicle screw placement with the assistance of lateral plain radiography. J Spinal Disord., Vol. 9, No. 4, (Aug. 1996) 334-8, ISSN: 0895-0385

Rampersaud Y.R., Foley K.F. (2000). Image-guided spinal surgery. Op Tech Orthoped, Vol. 10, (2000) 64-8

Rampersaud, Y.R., Simon, D.A., \& Foley, K.T. (2001), Accuracy requirements for imageguided spinal pedicle screw placement. Spine, Vol. 26, No. 4, (February 2001) 352359, ISSN: 0362-2436

Raynor ,B.L. et al. (2002). Can triggered electromyograph thresholds predict safe thoracic pedicle screw placement? Spine, Vol. 27, No. 18, (September 2002) 2030-2035, ISSN: $0362-2436$

Reidy, D.P. et al. (2001). Evaluation of electromyographic monitoring during insertion of thoracic pedicle screws. J Bone Joint Surg Br, Vol. 83, No. 7, (September 2001) 10091014, ISSN: 0301-620X

Schlenzka, D., Laine, T., \& Lund, T. (2000). Computer-assisted spine surgery. Eur Spine J, Vol. 9, No. 1, (February 2000) S57-S64, ISSN: 0940-6719

Schulze, C.J., Munzinger, E., \& Weber, U. (1998). Clinical relevance of accuracy of pedicle screw placement. A computed tomographic-supported analysis. Spine, Vol. 23, No. 20, (October 1998) 2215-2221, ISSN: 0362-2436

Schwarzenbach, O. et al. (1997). Accuracy of computer-assisted pedicle screw placement: An in-vivo computed tomography analysis. Spine, Vol. 22, No. 4, (February 1997) 452-8, ISSN: 0362-2436

Simon, D.A., \& Lavallee, S. (1998). Medical Imaging and Registration in Computer Assisted Surgery. Clin Orthop Relat Res, Vol. 354, (September 1998) 8-16, ISSN: 0009-921X

Shoham, M. et al. (2003). Bone-Mounted Miniature Robot for Surgical Procedures: Concept and Clinical Applications IEEE Transactions on Robotics and Automation, Vol. 19, No. 5, (October 2003) 893-901, ISSN: 1042-296X

Suk, S. et al. (1995). Segmental pedicle screw fixation in the treatment of thoracic idiopathic scoliosis. Spine, Vol. 20, No. 12, (June 1995) 1399-1405, ISSN: 0362-2436

Taylor, R. H., \& Stoianovici, D. (2003). Medical Robotics in Computer-Integrated Surgery, IEEE Transactions on Robotics and Automation, Vol. 19, No. 5, (October 2003) 765-781, ISSN: 1042-296X

Togawa, D. et al. (2007). Bone-mounted miniature robotic guidance for pedicle screw and translaminar facet screw placement: part 2--Evaluation of system accuracy. Neurosurgery, Vol. 60, No. 2, (February 2007) ONS129-139, ISSN: 0148-396X

Vaccaro, A.R. et al. (1995a). Placement of pedicle screws in the thoracic spine: Part I. Morphometric analysis of the thoracic vertebrae. J Bone Joint Surg Am, Vol. 77, No. 8, (August 1995) 1193-1199, ISSN: 0021-9355

Vaccaro, A.R. et al. (1995b). Placement of pedicle screws in the thoracic spine: Part II. An anatomical and radiographic assessment. J Bone Joint Surg Am, Vol. 77, No. 8, (August 1995) 1200-1206, ISSN: 0021-9355

Weinstein, J.N. et al. (1988). Spinal pedicle fixation: Reliability and validity of roentgenogram-based assessment and surgical factors on successful screw placement. Spine, Vol. 13, No. 9, (September 1988) 1012-1018, ISSN: 0021-9355 
Welch, W.C. et al. (1997). Evaluation with evoked and spontaneous electromyography during lumbar instrumentation: A prospective study. J Neurosurg, Vol. 87, No. 3, (September 1997) 397-402, ISSN: 0022-3085

$\mathrm{Xu}, \mathrm{R}$. et al. (1998). Anatomic considerations of pedicle screw placement in the thoracic spine: Roy-Camille technique versus open lamina technique. Spine, Vol. 23, No. 9, (1998) 1065-1068, ISSN: 0021-9355 


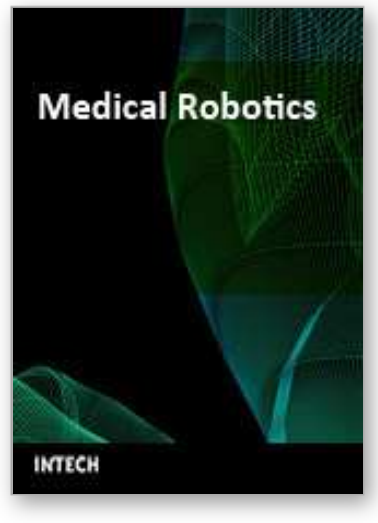

\author{
Medical Robotics \\ Edited by Vanja Bozovic
}

ISBN 978-3-902613-18-9

Hard cover, 526 pages

Publisher I-Tech Education and Publishing

Published online 01, January, 2008

Published in print edition January, 2008

The first generation of surgical robots are already being installed in a number of operating rooms around the world. Robotics is being introduced to medicine because it allows for unprecedented control and precision of surgical instruments in minimally invasive procedures. So far, robots have been used to position an endoscope, perform gallbladder surgery and correct gastroesophogeal reflux and heartburn. The ultimate goal of the robotic surgery field is to design a robot that can be used to perform closed-chest, beating-heart surgery. The use of robotics in surgery will expand over the next decades without any doubt. Minimally Invasive Surgery (MIS) is a revolutionary approach in surgery. In MIS, the operation is performed with instruments and viewing equipment inserted into the body through small incisions created by the surgeon, in contrast to open surgery with large incisions. This minimizes surgical trauma and damage to healthy tissue, resulting in shorter patient recovery time. The aim of this book is to provide an overview of the state-of-art, to present new ideas, original results and practical experiences in this expanding area. Nevertheless, many chapters in the book concern advanced research on this growing area. The book provides critical analysis of clinical trials, assessment of the benefits and risks of the application of these technologies. This book is certainly a small sample of the research activity on Medical Robotics going on around the globe as you read it, but it surely covers a good deal of what has been done in the field recently, and as such it works as a valuable source for researchers interested in the involved subjects, whether they are currently "medical roboticists" or not.

\title{
How to reference
}

In order to correctly reference this scholarly work, feel free to copy and paste the following:

Y. Barzilay, L. Kaplan and M. Liebergall (2008). Miniature Robotic Guidance for Spine Surgery, Medical Robotics, Vanja Bozovic (Ed.), ISBN: 978-3-902613-18-9, InTech, Available from:

http://www.intechopen.com/books/medical_robotics/miniature_robotic_guidance_for_spine_surgery

\section{INTECH}

open science | open minds

\section{InTech Europe}

University Campus STeP Ri

Slavka Krautzeka 83/A

51000 Rijeka, Croatia

Phone: +385 (51) 770447

\section{InTech China}

Unit 405, Office Block, Hotel Equatorial Shanghai

No.65, Yan An Road (West), Shanghai, 200040, China

中国上海市延安西路65号上海国际贵都大饭店办公楼 405 单元

Phone: +86-21-62489820 
Fax: +385 (51) 686166

Fax: +86-21-62489821

www.intechopen.com 
(C) 2008 The Author(s). Licensee IntechOpen. This chapter is distributed under the terms of the Creative Commons Attribution-NonCommercialShareAlike-3.0 License, which permits use, distribution and reproduction for non-commercial purposes, provided the original is properly cited and derivative works building on this content are distributed under the same license. 